\title{
Direct UV writing of optical waveguides in congruent undoped lithium niobate
}

\author{
S. Mailis, C. Riziotis, I. T. Wellington, P. G. R. Smith, R. W. Eason \\ Optoelectronics Research Centre, \\ University of Southampton, Highfield, \\ Southampton, SO17 IBJ, \\ $U K$. \\ tel: ++44 (0)2380 593141 fax: ++44 (0)2380 593142, email: sm(a)orc.soton.ac.uk
}

The strong coupling between lithium niobate and ultra violet (UV) radiation has been shown to modify the chemical properties of the surface of this material [1]. Furthermore, as is demonstrated here, continuous wave (c.w.) ultra violet (UV) light can also modify the index of refraction within a short depth (consistent with the short absorption length of UV radiation) below the exposed lithium niobate surface.

Illumination of various cut lithium niobate surfaces with c.w. UV laser light (at $244 \mathrm{~nm}$ ) has proven to induce an increase of the extraordinary index of refraction thus enabling the construction of optical waveguides.

In order to investigate the quality of such waveguide structures $z$ cut and $y$ cut lithium niobate samples were scanned under the focussed frequency doubled $\mathrm{Ar}^{+}$laser $(244 \mathrm{~nm})$ laser beam using a set of precision $\mathrm{x}-\mathrm{y}$ translation stages to produce sets of channel waveguides under various exposure conditions. The exposure could be modified by controlling the translation stage velocity, the laser power or the focal spot size of the laser beam. The energy fluence range used in the present experiments was between $10 \mathrm{~J} / \mathrm{cm}^{2}$ and $8000 \mathrm{~J} / \mathrm{cm}^{2}$ by varying all three exposure parameters.

Refractive index changes of order $10^{-3}-10^{-4}$, depending on the exposure conditions, were deduced from numerical aperture measurements of single mode waveguides at visible wavelengths which were performed using a HeNe laser $(633 \mathrm{~nm})$. However multimode waveguide structures were observed for higher UV exposure levels, suggesting larger index changes.

Brief chemical etching (using HF acid) of the channel waveguide cross section provided enough optical contrast to make the laser affected area visible under optical microscope investigation as is shown in figure 1 . The waveguide array was fabricated using a UV laser beam spot diameter of $3.5 \mu \mathrm{m}\left(\right.$ at $\left.1 / \mathrm{e}^{2}\right)$ and energy fluence of $90 \mathrm{~J} / \mathrm{cm}^{2}$. The near field mode profile, which is shown in the inset of figure 1 for comparison, was acquired from an identically exposed (not etched) UV written channel waveguide structure.

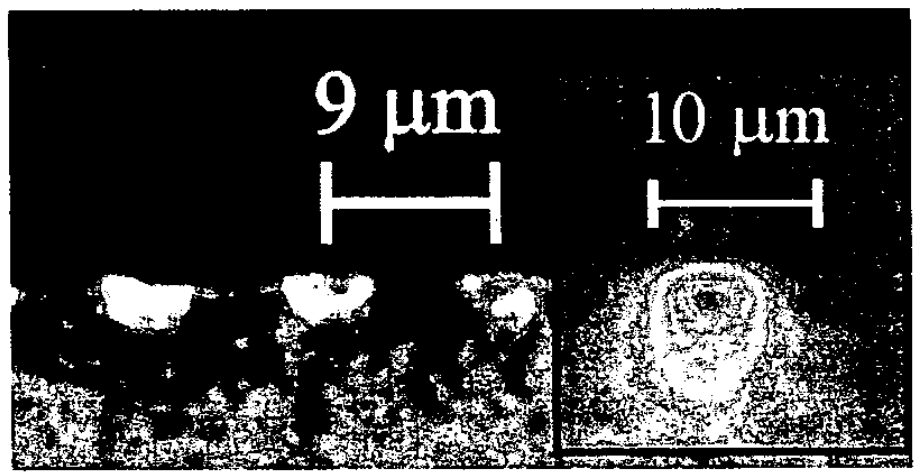

Figure 1. Optical microscope picture showing the ctched cross section of $-\mathrm{z}$ face UV cxposed channels. The channcl width is $\sim 4 \mu \mathrm{m}$ and they are separated by $9 \mu \mathrm{m}$. Inset: near ficld mode profile (at $633 \mathrm{~nm}$ ) from identically exposed UV written waveguide structurc.

Optical loss values which have been obtained on a set of identical waveguides, using visible $(633 \mathrm{~nm})$ radiation from a $\mathrm{HeNe}$ laser, have been measured to be as low as $0.7 \mathrm{~dB} / \mathrm{cm}$. The strong photorefractive damage which has been observed in the UV written waveguides at visible wavelengths was held responsible for the measured transmission loss values. However, photorefractive damage is expected to be negligible for the longer telecom wavelengths $(\sim 1.5 \mu \mathrm{m})$ and we will report the waveguide transmission characteristics as well as the optical transmission loss at these wavelengths.

Further research on the characterization of UV written waveguides at longer wavelengths, determination of the physical origin responsible for the observed refractive index change using surface analysis techniques as well as fabrication of complex waveguide structures such as $\mathrm{Y}$-junctions and interferometers is currently under way.

References

[1] S. Mailis, C. Riziotis, P. G. R. Smith, J. G. Scott, R. W. Eason, accepted for publication Appl. Surface Sci. 